\title{
Allelopathic effect of Albizia saman F. Muell on three widely cultivated Indian crop species
}

\author{
Satabdi Ghosh ${ }^{1}$, Kutubuddin A. Molla ${ }^{1}$ and Kasinath $\mathrm{Ghosh}^{2 *}$ \\ ${ }^{1}$ (Department of Botany, University of Calcutta, 35, Ballygunge Circular Road, Kolkata 700019, India) \\ ${ }^{2}$ (Department of Botany, Scottish Church College, 1 \& 3 Urquhart Square, Kolkata 700 006, India)
}

\begin{abstract}
A study with completely randomized design in factorial arrangement and under in vitro conditions was conducted to assess the allelopathic effect of Albizia saman F.Muell leaf leachate on three popular crop species, namely Amaranthus viridis L.(vegetable crop), Brassica campestris L. var dichotoma Wall. (oil crop) and Oryza sativa L.cv.Pankaj (cereal crop). Different concentrations (0, 1, 2 and 4\%) of leaf leachate were applied to seeds of all test plants to investigate their effect on germination and seedling growth. Result showed that rice $(O$. sativa) is least sensitive both in terms of germination and of seedling growth to the leaf leachate. The mustard plant (B. campestris) was found to be affected highly in the presence of leaf leachate. Germination percentage was gradually decreased over the control with increasing concentration of leaf leachate. In $4 \%$ leaf leachate application, the germination was inhibited about $91 \%$ over the control. A. viridis was proved as moderately sensitive to the leaf leachate. Gradual decrease in root length of A. viridis was observed with increasing concentration of leachate. Hypocotyl length of A. viridis at $2 \%$ and $4 \%$ was found to be stimulated than the hypocotyl length at $1 \%$. The study revealed that the plant S. saman has inhibitory effect on B. campestris and A. viridis, whereas rice plant is resistant to the effect of leaf leachate.
\end{abstract}

Keywords: Albizia saman, Allelopathy, Amaranthus viridis, Brassica campestris, Oryza sativa.

\section{Introduction}

Allelopathy is the inhibition of germination, growth or metabolism of one plant due to release of organic compounds by another plant [1] and this form of interference is basically different from competition which acts through the depletion of resources [2, 3, 4]. Allelopathy is also an expression of ecological phenomenon which is the normal constituents of environment of terrestrial plants [5]. Albizia saman is believed to be native is Northern South America and in Central America. It is now widespread from Mexico, Peru, Bolivia and Brazil. This tree is cultivated and naturalized throughout the tropics. In these areas it occurs in lowelevation, dry forests and grassland habitats.

The plant is a tree generally attains maximum height of $15-25 \mathrm{~m}$ with a canopy diameter wider than the height of the tree. The tree usually has a short, stout trunk of about 1-2 $\mathrm{m}$ in diameter at breast height. Leaves are alternately arranged along twigs and have a prominent swelling (pulvinus) at the petiole base, thread like stipules are present, the leaf blades are twice- even- pinnately compound, arranged in 2-6 pairs of pinnae, each pinna bearing 6-16 diamond shaped leaflets, shiny green above, dull and finely hairy beneath. The tiny flowers are massed in pinkish heads $5-6 \mathrm{~cm}$ across and about $4 \mathrm{~cm}$ in height. The long bicoloured stamens (white in lower half and reddish above) give the whole inflorescence the appearance of a powder puff. Usually only one flower per inflorescence (rarely two) is pollinated and forms a fruit. Fruit is pod and in matured condition it is blackish brown, oblong, lumpy, 10-20 cm long, $15-19 \mathrm{~mm}$ wide, slightly curved, cracking irregularly and filled with a sticky brownish, sweet and edible pulp. Seeds are oblong- ellipsoid. Seeds are dispersed by domestic livestocks. The tree is common on small farms along roads, river banks, in parks and pastures. It is now planted for shade in plantation of coffee, cocoa, vanilla, young nutmeg, and teak. During dry periods, the tree looses leaves and remains leafless for a period of weeks.

The leaves of A. saman display antimicrobial activity [6]. The leaves were reported to constitute tannins, flavonoids, steroids, saponins, cardiac glycosides, and terpenoids [7]. Although the allelopathic potential of this plant was reported [8] but the allelochemicals were not elucidated. So the purpose of the present study was to elucidate the inhibitory effect of different concentration of leaf leachates of A. saman on some common agricultural crops of India. The present work is concerned with the effect of leaf leachates of Albizia saman on the seed germination and seedling growth of Brassica campestris, Oryza sativa and Amaranthus viridis.

The survey of literature reveals that water leachates of seed, stem and leaf of plant reduces rate of germination \& early seedling growth of Zea mays L., Triticum aestivum L.and Albizia lebbeck L. Benth [8]. The leaf leachate of Albizia saman in different concentration inhibit germination and seedling growth of Cicer arietinum L., Raphanus sativus L., Vigna unguiculala (L) Walp, Phaseolus mungo L. and Brassica juncea L. [9]. 
The present work is concerned with the effect of leaf leachates of Albizia saman F. Muell on seed germination and seedling growth of Brassica campestris L., Oryza sativa L. and Amaranthus viridis L.

\section{Materials And Methods \\ 2.1. Collection of leaves and preparation of leachate of Albizia saman}

Dicot leaves of vigorously growing individuals of Albizia saman were collected from certain areas of Khanyan under Hooghly District (West Bengal) during January to April 2012, 2013. Leachates were prepared by soaking $1 \mathrm{gm}$ of dried leaves in $100 \mathrm{ml}$ of sterile distilled water for 72 hours. Filtrate was taken in a volumetric flask. This is $1 \%$ leachate. In this way, $2 \%$ and $4 \%$ leachate was made.

\subsection{Bioassays and experimental design}

Three important agricultural crops: cereal crop rice (Oryza sativa L.), oil crop mustard (Brassica campestris L.) and vegetable crop Amaranthus viridis L. were selected as bioassay species. Seeds from all the three species were surface sterilized by washing with $0.45 \%$ sodium hypochlorite for $10 \mathrm{mins}$. Then the seeds were washed thoroughly with distilled water repeatedly to remove trace amount of hypochlorite. Each bioassay experiment was performed by placing 25 surface sterilized seeds in sterile petridish $(11 \mathrm{~cm}$ in diameter) lined with whatman filter paper.The seeds were then treated with $10 \mathrm{ml}$ of the $1 \%, 2 \%$ and $4 \%$ test solution and with water as control. The treatments were laid out in a completely randomized design with factorial arrangement in four replications. The petridishes were incubated at room temperature $\left(28 \pm 3^{\circ} \mathrm{C}\right)$ for 3 days.

\subsection{Data collection and statistical analysis}

Ratio of germination and elongation were calculated as described in an earlier report [10].

$\mathrm{RGR}=\mathrm{GR}_{\mathrm{T}} / \mathrm{GR}_{\mathrm{C}} \times 100$ where, $\mathrm{RGR}=$ relative germination ratio, $\mathrm{GR}_{\mathrm{T}}=$ germination ratio of test plant and $\mathrm{GR}_{\mathrm{C}}=$ germination ratio of control plant.

$\mathrm{RER}=\mathrm{ML}_{\mathrm{T}} / \mathrm{ML}_{\mathrm{C}} \times 100$ where, $\mathrm{RER}=$ relative elongation ratio, $\mathrm{ML}_{\mathrm{T}}=$ mean length of test plant and $\mathrm{ML}_{\mathrm{C}}=$ mean length of control plant.

For the calculation of percentage of inhibitory effect on the elongation, a previously described formula was used [11]: $\quad \mathrm{I}=100-\left(\mathrm{E}_{\mathrm{T}} / \mathrm{E}_{\mathrm{C}} \times 100\right)$ where, $I$ is the $\%$ inhibition, $\mathrm{E}_{\mathrm{T}}$ is the elongation of test plant and $\mathrm{E}_{\mathrm{C}}$ is the elongation of control plant.

The average data obtained from four experimental replication were analysed using Graphpad prism 5 software (GraphPad Software, CA, USA). One-way and two-way analyses of variance (ANOVAs) were used to compare the differences between the control and the test plants. $P<0.05$ was considered to be statistically significant.

\subsection{Germination}

\section{Results And Discussion}

Leachates of leaves of the plant inhibited the seed germination of mustard and Amaranthus but not that of rice. The germination percentage was significantly lower $(p<0.001)$ in all treatment $(1,2$ and $4 \%)$ plants than the control plants in case of Amaranthus (Fig- 1). The inhibitory effect gradually increased with progressive increase in concentration of the leachates. In case of mustard, the RGR value is significantly $(p<0.001)$ lower in the leachate treated set of seeds than that in the control water treated seeds. Among all the experimental set up for RGR determination, the lowest RGR value (9\%) was exhibited in mustard seeds treated with $4 \%$ leachate (Fig-2). Percentage of inhibition of germination was highest $(71.2 \%, 80.2 \%$ and $91 \%$ respectively in case of $1 \%$, $2 \%$ and $4 \%$ leachate) in case of mustard among all the three test species. On the other hand, the germination of rice was not affected by the presence of Albizia saman leaf leachate (Fig-3). Result showed that there was no significant difference ( $p$ value 0.8125 ) in treated plants when compared with the control plants. Among the test crops, the rice plant showed highest level of RGR value (100\% in both $1 \%$ and $2 \%$ leachate). But in case of $4 \%$ leachate, the RGR value (98\%) was slightly decreased than the control plants.

Allelopathic effects of different plant species like Parthenium [12], Eucalyptus [13], Albizia [8], Pinus [14] have been reported. In all the reports, the germination inhibitory potential had been increased with the increasing concentration of the leachate. Our findings also confer the similar result in two test plants Amaranthus and Brassica. Whereas rice germination was not inhibited by the water leachate of Albizia saman. The reduced germination percentage in Amaranthus and mustard could be due to the presence of water soluble toxic chemicals present in the leachate [15]. In a previous report, it was reported that lower concentration of leaf leachate of Albizia saman showed stimulatory effects on germination in some cases [9]. In our study, rice showed least sensitivity to Albizia saman leaf leachate. Phaseolus mungo also showed a lesser sensitivity to $A$. saman leaf leachate in an earlier report [9].

\subsection{Growth of seedling}


Result of the study of the effect of Albizia saman leaf leachate on the seedling growth of the three test species showed variation in different treatments. In Amaranthus and mustard plants, root lengths were significantly inhibited in all percentages of leaf leachate (Fig-4 \& 5). Highest level of root length inhibition (I value $92.26 \%$ ) was found in mustard seedling treated with $4 \%$ leachate. In rice plants, stimulation of root lengths were observed when $1 \%$ and $2 \%$ leaf leachate was applied. However, application of $4 \%$ leachate caused the inhibition of root length in rice (Fig-6).

Hypocotyls length was measured in Amaranthus and found to be significantly $(p=0.01)$ inhibited on $1 \%$ leachate application. However, application of $2 \%$ and $4 \%$ leachate resulted in hypocotyl length inhibition which is not significant statistically (Fig-4). In mustard seedling, the hypocotyl length was decreased progressively with increase in the concentration of $A$. saman leaf leachate concentration. At $4 \%$ leaf leachate treatment, dramatically the hypocotyl did not emerge at all after 3 days of treatment (Fig- 5). The differences in the length of hypocotyl were statistically significant $(p<0.0001)$ when compared with the control plants. On the other and, the shoot length was measured in case of control and treated rice plants as it shows hypogeal germination (Fig- 6). The difference between the mean shoot length of control rice plants and rice plants treated with $1 \%$ and $2 \%$ leachate was not significant statistically, whereas significant $(p=0.002)$ reduction in shoot length was found in rice plants treated with $4 \%$ leachate. Basmati Pak variety of rice has been proved to be sensitive to the allelopathic effect of sunflower [16].

Root lengths were found to be more sensitive than shoot length or hypocotyls length in response of leachate since they are the first organ to experience the effect of allelochemicals. Similar result was observed in several earlier reports $[17,8,18,19]$. The reduced rate of cell division due to the presence of allelochemicals, which might inhibit gibberellin and indoleacetic acid function may be the reason of reduction in root length [20]. The inhibitory effect on seedling growth is due to the release of different kinds of phytotoxic compounds, viz. phenolics, sesquiterpenes, p-cymene, ascaridole, aritazone and lactones, from the vegetative part of living plants $[21,22,23,24]$. This effect on rice proves that the rice is more tolerant to the allelopathic effect of $A$. saman than Brassica and Amaranthus seeds.

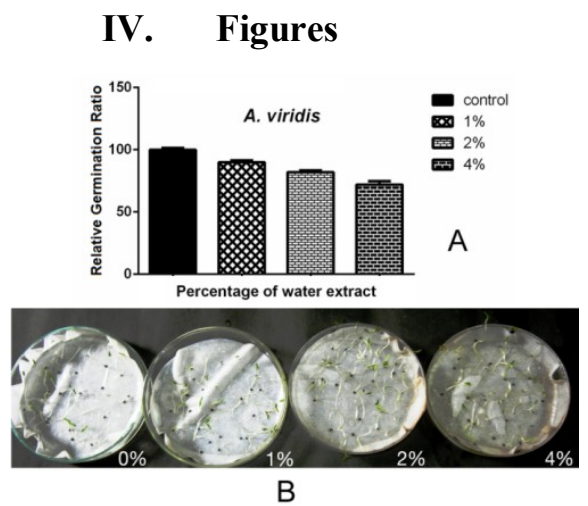

Figure 1: A) Effect of various concentrations of leaf leachate of Albizia saman on the germination of Amaranthus viridis seed. Each bar represents mean \pm standard error. B) Representative image of germination in bioassay plate treated with different concentration of leaf leachate showing inhibition at higher concentration.

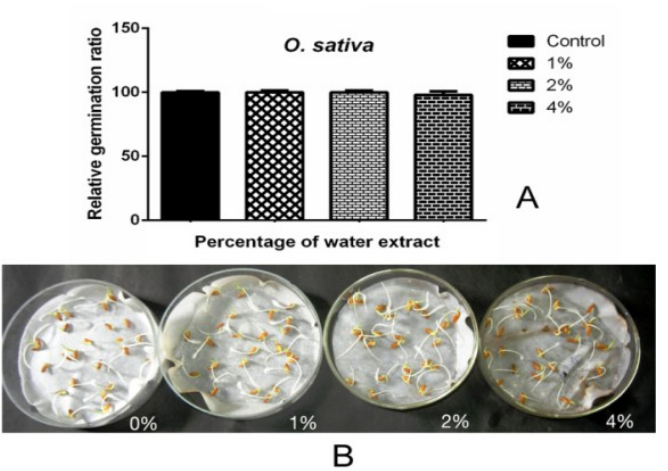

Figure 2: A) Effect of various concentrations of leaf leachate of Albizia saman on the germination of Oryza sativa seed. Each bar represents mean \pm standard error. B) Representative image of germination in bioassay plate treated with different concentration of leaf leachate showing no inhibition. 

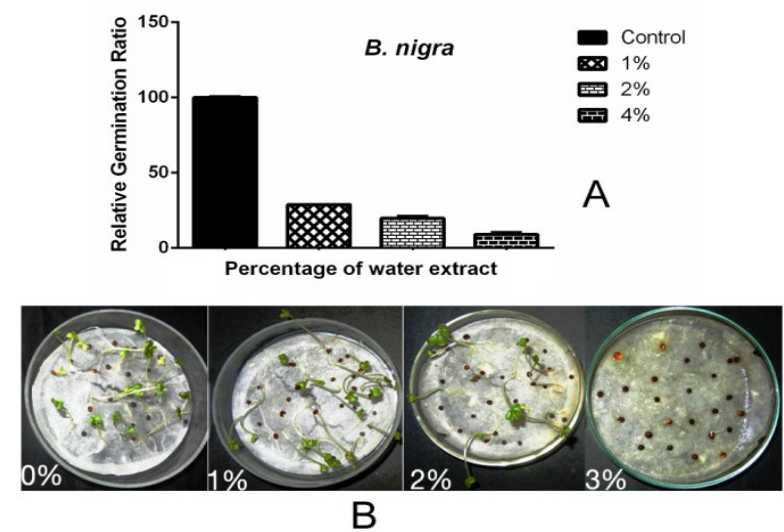

Figure 3: A) Effect of various concentrations of leaf leachate of Albizia saman on the germination of Brassica campestris seed. Each bar represents mean \pm standard error. B) Representative image of germination in bioassay plate treated with different concentration of leaf leachate showing inhibition at higher concentration.

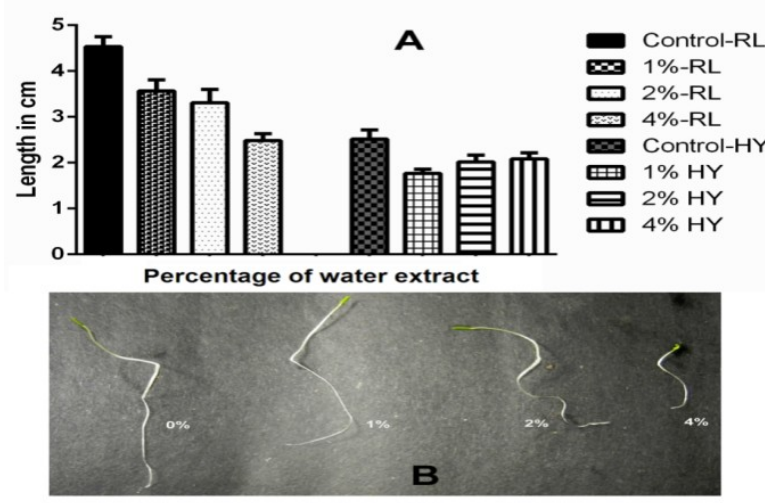

Figure 4: A) Effect of different concentration of Albizia saman leaf leachate on Amaranthus viridis seedling growth. RL stands for root length and HY stands for hypocotyls length. Mean \pm standard error is represented in each bar. B) Representative image of seedling growth inhibition with gradual increase in leaf leachate concentration.

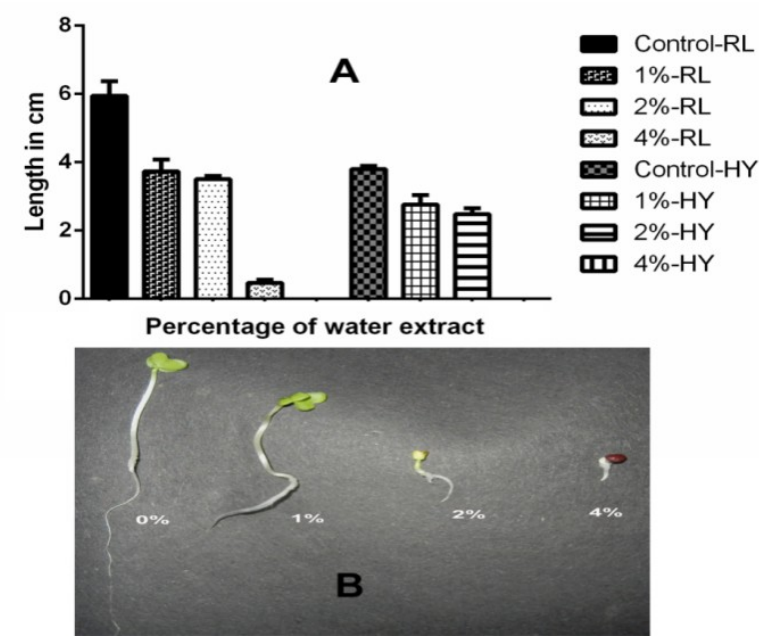

Figure 5: A) Effect of different concentration of Albizia saman leaf leachate on Brassica campestris seedling growth. RL stands for root length and HY stands for hypocotyls length. Mean \pm standard error is represented in each bar. B) Representative image of seedling growth inhibition with gradual increase in leaf leachate concentration. At $4 \%$ concentration, the hypocityl elongation was completely inhibited. 

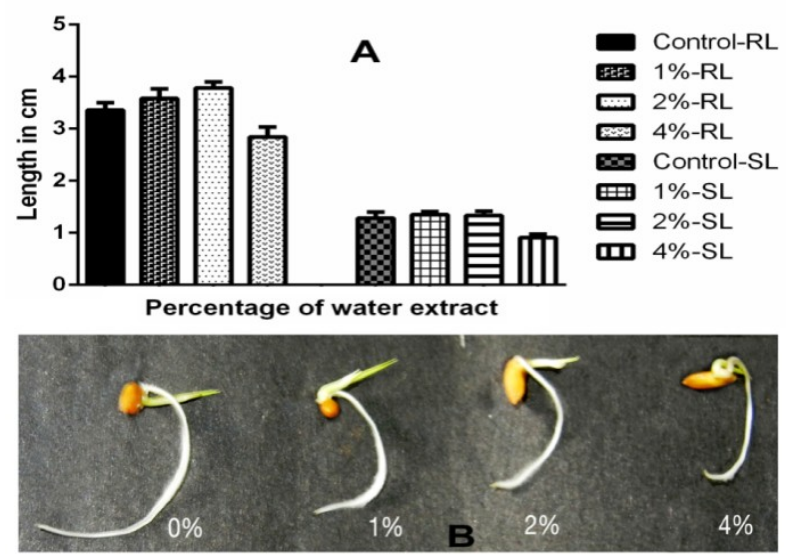

Figure 4: A) Effect of different concentration of Albizia saman leaf leachate on Oryza sativa seedling growth. RL stands for root length and SL stands for shoot length. Mean \pm standard error is represented in each bar. B) Representative image of seedling growth with gradual increase in leaf leachate concentration showing inhibition at $4 \%$.

\section{Conclusion}

It is evident from the present study that Albizia saman has allelopathic effect on mustard and Amaranthus, whereas it has less effect on rice. The result could explain the absence of other plant species specially dicot or stunted growth of individuals in the vicinity of the tree A. saman. As the A. saman plant is deciduous, the inhibitors leached out in the soil underneath and the adjoining area has an allelopathic effect on the dicot plant more than monocot. Though allelopathic potential analysis of a species through laboratory bioassays are of great importance, field studies, ecological effect determination and detection of chemical nature of the inhibitors present in the leachate is necessary before incorporating the species in an agroforestry system. So, it is suggested that Albizia saman should only be planted in the locality, not adjoining to any cultivated land.

\section{Acknowledgement}

We highly acknowledge the support from Mrs. Sikha Ghosh and Dr. John Abraham, Principal, Scottish Church College, Kolkata.

\section{Reference}

[1]. B. Del moral, and Cates, Allelopathy in Washington vegetation. Ecology, 52, 1971, 1030-1037.

[2]. C.H. Muller, The role of chemical inhibition (allelopathy) in vegetational composition. Bulletin of Torrey Botanical club, 93, 1966, 332-351

[3]. H.B. Tukey, Implications of allelopathy in agricultural plant science, Botanical Review, 35, 1969, 1-16

[4]. R.O. Tinnin and C.H. Muller, The allelopathic potential of Avena fatus : Influence on herb distribution, Bulletin of Torrey botanical Club, 99, 1971, 243-250

[5]. S.C. Datta, and S.P. Sinha-roy, Allelopathy and inhibitors. Science and Culture, 40,1975, 47-59

[6]. M.P. Raghavendra, S. Satish and K.A. Raveesha, In Vitro Antibacterial Potential of Alkaloids of Samanea sa- man (Jacq.) Merr. against Xanthomonas and Human Pa- thogenic Bacteria. World Journal of Agricultural Sciences, 4(1), 2008, 100-105.

[7]. R.N. Prasad, S. Viswanathan, J.R. Devi, V. Nayak, V.C. Swetha, B.R. Archana, N. Parathasarathy and J. Rajku- mar, Preliminary Phytochemical Screening and Antim- icrobial Activity of Samanea saman. Journal of Me-dicinal Plants Research, 2(10), 2008, 268- 270 .

[8]. M. Noor and M.A. Khan, Allelopathic Potential of Albizia samans Merr., Pakistan Journal of Botany, 26, 1994, 139-147.

[9]. R.A.T.M. Hoque, M.B. Uddin, R. Ahmed and M.K. Hossain, Suppressive effect of aqueous extracts of Azadirachta indica leaf on some initial growth parameter of six common agricultural crops. Asian Journal of Plant Sciences, 2(10), 2003, 738-742.

[10]. B.J. Rho and B.S. Kil, Influence of phytotoxin from Pinus rigida on the selected plants, Journal of Nature and Science, 5,1986, 1927.

[11]. M.P. Surendra and K.B. Pota, On the allelopathic potentials of root exudates from different ages of Celosia argenta Linn, National Academy of Science Letters, $1,1978,56-58$.

[12]. A. Netsere and E. Mendesil, Allelopathic effects of Parthenium hysterophorus L. aqueous extracts on soybean (Glycine max L.) and haricot bean (Phaseolus vulgaris L.) seed germination, shoot and root growth and dry matter production, Journal of Applied botany and Food Quality, 84, 2011, 219 - 222

[13]. R. Ahmed, A.T.M.R. Hoque, and M.K. Hossain, Allelopathic effects of leaf litters of Eucalyptus camaldulensis on some forest and agricultural crops, Journal of Forest Research, 19, 2008, 19-24.

[14]. B. S. Kil, Allelopathic effects of five pine species in Korea, in Phytochemical Ecology: Allelochemicals, Mycotoxins, and Insect Pheromones and Allelomones, Academia Sinica, 9,1989, 81-100.

[15]. B. S. Kill and K. W. Yun, Allelopathic effects of water extracts of Artemisia princes var. orientalis onselected plant species. Journal of Chemical Ecology, 18, 1992, 39-51.

[16]. U. Bashir, A. Javaid, and R. Bajwa, Allelopathic effects of sunflower residue on growth of rice and subsequent wheat crop, Chilean Journal Agricultural Research, 72 (3), 2012, 326-331 
[17]. A.E. Smith, The potential allelopathic characteristics of bitter sneezeweed (Helenium amarum), Weed Science, 37(5), 1989, 665669.

[18]. T. Tefera, Allelopathic effects of Parthenium hysterphorus extracts on seed germination and seedling growth of Eragrostis tef (zucc.) Trotter, Journal of Agronomy and Crop Science, 188(5), 2002, 306-310.

[19]. M. Wakjira, D. Adugna, G. Berecha, Determining slice thickness of banana (Musa spp) for enclosed drying using solar drying using solar cabinet dryer under Ethiobian condition, American Journal of food technology, 6(7), 2011, 568-580.

[20]. M. Tomaszewski, K.V. Thimann, Interactions of phenolic acids, metallic ions and chelating agents on auxin induced growth. Plant physiology 41, 1966, 1443-1454.

[21]. W.A. Stephen and M.S. Sowerby, Allelopathic potential of the weed Parthenium hysterophorus L. in Australia. Plant Protection, $11,1996,20-23$

[22]. H.C. Evans, Parthenium hysterophorus: a review of its weed status and possibilities for biological control. Biocontrol News and Information, 18, 1997, 89-98.

[23]. R.G. Belz, C.F. Reinhardt, L.C. Foxcroft, and H. Karl, Residual allelopathy in Parthenium hysterophorus L.. Does parthenin play a leading role?, Crop Protection 26, 2007, 237-245.

[24]. S.C. Datta and K.N. Ghosh, Allelopathy in two species of Chenopodium - inhibition of germination and seedling growth of certain weeds, Acta Societatis Botanicorum Poloniae, 56(2), 1987, 257-270. 